\title{
ARQUITETAS DA VIDA, VIVENDO ENTRE RUÍNAS: MEMÓRIA INDIVIDUAL, GERACIONAL E INTERGERACIONAL EM NAS TUAS MÃOS, DE INÊS PEDROSA
}

\author{
Denise Almeida Silva \\ (Universidade Regional Integrada do \\ Alto Uruguai e das Missões)
}

\section{RESUMO}

Este estudo apresenta uma análise do papel da memória individual e social no romance Nas tuas mãos, de Inês Pedrosa. A obra narra a vida de três mulheres, cujas memórias são apresentadas sucessivamente, por meio de três suportes distintos: diário, álbum de fotos e cartas; juntos, os relatos de avó, mãe e filha cobrem aproximadamente 60 anos da história de Portugal, do entre-guerras às guerras pela preservação das possessões ultramarinas, passando, também, pelo Estado Novo salazarista. As complexas imbricações entre memória individual e social são estudadas com suporte no pensamento de Maurice Halbwachs e de Aleida Assmann, cuja ideia de bipartição da memória social em geracional e intergeracional adoto; a relevância dos suportes materiais de memória a que cada uma das personagens recorre é pensada a partir de estudos de Philippe Lejeune, Roland Barthes e Pierre Bourdieu.

PALAVRAS-CHAVE: memória individual, memória social, Inês Pedrosa.

\section{ABSTRACT}

This study is an analysis of the role of individual and social memory in Inês Pedrosa's novel Nas tuas mãos, which chronicles the lives of three women, whose memories are presented successively through three different media: journal, photo album and letters. Together, the registers of the grandmother, mother and daughter cover approximately 60 years of Portugal history, from the interwar years to the wars for the preservation of the overseas 
possessions, encompassing, yet, Salazar's Estado Novo ("New State"). The study of the complex overlapping between individual and social memory relies on the thought of Maurice Halbwachs and Aleida Assmann, whose bipartition of social memory in generational and intergenerational I adopt; studies from Philippe Lejeune, Roland Barthes and Pierre Bourdieu underlie the analysis of the relevance of the distinct memory supports to which each of the character relies.

KEYWORDS: individual memory, social memory, Inês Pedrosa.

\section{INTRODUÇÃO}

Nas tuas mãos (1987), segundo romance de Inês Pedrosa, narra a vida de três de mulheres, cujas memórias são apresentadas sucessivamente, por meio de três suportes distintos - Jenny, a avó, recorre a um diário para reavaliar seu relacionamento com António; sua filha, Camila, rememora amores e desamores, e os anos de ativismo político a partir de um álbum de fotografias; por fim, Natália escreve cartas à avó, com quem entretém grande cumplicidade, o que lhe permite reavaliar, com muita franqueza, sua carreira, matrimônio, busca pelo pai e por um grande amor.

Em seu contexto sociocultural específico, cada uma delas terá que transitar entre o amor e sua negação, definir seu lugar enquanto mulher e amante, construir e reconstruir suas vidas entre o ser e o ter. Através do entrecruzamento de memórias, o leitor reconstrói, a partir de diferentes olhares, não somente a história vital de cada uma, mas também sessenta anos da história de Portugal, de 1934, quando Pedro e António se conhecem, a 1994, data em que é escrita a última das cartas de Natália. Alusões a marcos históricos que coincidem com datas marcantes na vida dos personagens fazem a narração retroceder ainda mais, a 1914, ano que, no romance, não remete ao início da Primeira Guerra Mundial, mas ao assassinato de Sidónio Pais, militar e político português, a 14 de dezembro de $1914,{ }^{1}$ que é, também, a data do nascimento do personagem Delfim Velleno.

Tendo vindo ao mundo no período final da Primeira Guerra Mundial, e havendo encontrado seu grande amor no verão de 1935, Jennifer teve seu período formativo situado no entre-guerras. Dirigindo-se retrospectivamente a António, em seu diário, observa: "Nem os escombros de duas guerras mundiais num só século conseguiram abrir-nos os olhos para o risível valor de nossos segredos, António." (PEDROSA, 2011, p. 38). A alusão a escombros não é fortuita, e encontra-se ligada a uma metáfora de construção e reconstrução que perpassa todo o romance. "No fim da guerra", registra Jennifer, "as pessoas descobriram-se entre ruínas e acreditaram que o mundo podia salvar-se através da construção.” (PEDROSA, 2011, p. 18).

Para além da reconstrução material, havia que (re)construir vidas, repensar valores, estabelecer prioridade: era, enfim, tempo de sobrevi- 
ver a si mesmo. Dessa forma, conquanto apenas Natália exerça a profissão de arquiteta, a metáfora da construção de vidas é relevante para a análise das três personagens, referindo-se tanto à construção das opções vitais de cada uma, como ao trabalho de memória que as sustenta.

Seja nas ruínas do entre-guerras, nos atribulados anos do Estado Novo salazarista, ou, ainda, no período de guerras de independência das colônias ultramarinas que se seguiu ao 25 de Abril, essas três mulheres símbolos de suas gerações - veem-se envolvidas na tarefa de arquitetar suas vidas, processo em que a memória, entendida na construção tanto do lembrar como do esquecer, desempenha papel relevante. Este estudo analisa as imbricações entre a memória individual e social dessas três mulheres, com base, sobretudo, nos estudos de Maurice Halbwachs e de Aleida Assmann, que refina o pensamento do sociólogo francês acerca da memória coletiva, de forma a descrever melhor sua complexidade. Para o benefício dos leitores não familiarizados com os estudos de Halbwachs e Aleida Assmann, e para prover uma caracterização geral introdutória sobre a memória no romance, resenho a seguir, brevemente, os principais pressupostos teóricos desses autores, relacionando-os à obra em estudo. Na sequência, estudo o entrecruzamento das memórias das personagens a partir dos suportes materiais específicos a que cada uma delas recorre, os quais são pensados, sobretudo, a partir dos estudos de Lejeune (2008) acerca das escritas do eu, e de Barthes (2008) e Bourdieu (1965) acerca da fotografia.

\section{TRÊS MULHERES E UMA NAÇÃO: MEMÓRIA INDIVIDUAL E SOCIAL}

Na concepção de Halbwachs (2006, p. 91), "em medida muito grande, a lembrança é uma reconstrução do passado com a ajuda de dados tomados de empréstimo ao presente e preparados por outras reconstruções feitas em épocas anteriores e de onde a imagem de outrora já saiu bastante alterada." (HALBWACHS, 2006, p. 91) Alimentada e dependente de correntes do pensamento coletivo, a memória individual enraíza-se na encruzilhada de múltiplas solidariedades, pois, para evocar o próprio passado, o indivíduo, em geral, precisa recorrer a lembranças de outros. Quando essas duas memórias se interpenetram, a memória individual pode preencher lacunas ou tornar mais precisas algumas lembranças com base na memória coletiva.

Essa compreensão da memória é importante porque o romance Nas tuas mãos é tramado a partir do entrecruzamento das memórias das três personagens principais. Centra-se, sobretudo, nos relacionamentos entre Jennifer e António, Camila e Eduardo/Xavier, e Natália e Álvaro, já que as prioridades e escolhas de cada uma delas giram ao redor de sua concepção de amor, que, por sua vez, se atrela a seu conceito de ser e do lugar que ocupam, enquanto mulheres, na sociedade; mudanças nessas concepções fornecem índices das modificações de valores intergeracionais. 
Uma vez que a memória é a matéria a partir da qual experiências individuais, relações interpessoais, senso de responsabilidade e autoimagem se tecem, é evidente seu papel nesse processo: à medida que estruturas sociais de relevância e sistemas de valores individuais mudam, o que antes era considerado importante retrocede a segundo plano, e o que até ali não despertava atenção pede, agora, por atenção retrospectiva.

Evidenciam-se, no romance, aspectos não só da memória individual como da memória social, esta última considerada tanto em sua feição intergeracional como geracional. Recorro, aqui, à tipologia de Aleida Assmann que, embora concordando com Maurice Halbwachs quanto à existência de complexas interações entre a memória individual e a coletiva, propõe uma classificação que, além da memória individual, compreende três outros níveis ou formatos de memória: a social, a política e a cultural.

Aleida Assmann distingue, na memória individual, a memória procedural, que armazena habilidades corporais e movimentos, a semântica, ligada à aprendizagem consciente, e a episódica, que processa experiências autobiográficas. Tal memória é idiossincrática, necessariamente ligada a uma experiência específica no mundo e, portanto, não intercambiável. Fragmentária e randômica, evoca cenas sem ordem, sequência ou coesão. Assim, por exemplo, Jennifer passa rapidamente da recordação da infância à memória de António, voltando em seguida ao tempo presente:

Tenho outra vez oito anos, deito-me sobre a relva, mas ela não cede ao meu peso de menina com aquela docilidade que recordo; a terra é dura, o seu cheiro violento, doem-me os ossos, o sol rasga-me os olhos, sufoca-me o peito. E tu ris-te de mim, António: beijas a boca a minha mãe e riem-se de mim os dois. [...]

A Camila contratou uma espia para viver comigo [...] (PEDROSA, 2011, p. 83-84)

Apesar de fragmentaria e randômica, a memória episódica não existe em completo isolamento, e é ligada a uma rede maior de outras memórias individuais e às memórias dos outros, formando redes de associação e comunicação nas quais a memória é contínua e socialmente readaptada, seja porque é substanciada e corroborada, ou porque é desafiada e corrigida. Quando, porém, associada a uma narrativa maior, que retrospectivamente lhe fornece forma e estrutura, a memória episódica perde seu caráter randômico, como é o caso da sequência narrativa do diário, dos textos feitos a partir da observação de fotos e das cartas neste romance.

As redes formadas pela memória individual e outras memórias são, como já exposto, elementos básicos nas postulações elaboradas por Halbwachs, que defende a noção de que memórias individuais mudam a partir do momento em que figuram em um conjunto que não mais é a consciência individual. Este é um ponto relevante para a análise do romance em estudo, principalmente tendo em vista a maneira como Jennifer 
constrói sua memória à medida que se altera seu relacionamento com respeito aos que lhe são mais caros. Já viúva, necessita preservar uma imagem idealizada de António, o que a leva a cultivar uma certa memória seletiva: "Não me lembro da experiência da dor. Uma das vantagens do envelhecimento é conseguirmos esquecer aquilo que não apetece recordar." (PEDROSA, 2011, p. 24).

Uma vez que Nas tuas mãos expõe a experiência pessoal e intergeracional que nasce da convivência entre avó, mãe, neta e seu círculo de amizades, tornam-se relevantes, para sua análise, as categorias de memória fundadas na experiência vivida propostas por Aleida Assmann. Para essa pensadora, a memória individual e a social são corporificadas; por outro lado, as memórias política e cultural são mediadas, e necessitam de suportes mais duráveis, signos externos, e representações materiais, recorrendo a bibliotecas, museus e monumentos. Estas últimas formas de memória são transgeracionais, de longo prazo; já a memória social caracteriza-se como intergeracional, sendo reciclada durante o período de aproximadamente oitenta a cem anos, que corresponde ao tempo durante o qual gerações de uma família - três, em geral, tal como no romance de Pedrosa - existem simultaneamente, formando uma comunidade de experiências, histórias e memórias compartilhadas.

Contudo, memórias são compartilhadas não somente com membros da família, amigos e vizinhos, mas com contemporâneos: uma forma de memória social é a memória geracional, compartilhada por um grupo, mais ou menos da mesma idade, que testemunhou os mesmos eventos históricos, partilhando quadros comuns de crenças, valores, hábitos e atitudes.

Essa concepção de memória geracional se aproxima da noção de história de Maurice Halbwachs, para quem o termo significa "não uma sucessão cronológica de eventos e datas, mas tudo o que faz com que um período se distinga dos outros" (HALBWACHS, 2006, p. 79). Assim, tanto o assassinato de Sidónio como numerosos outros eventos da história de Portugal que servem de suporte à memória das personagens correspondem à história vivida, posta do ponto de vista das personagens e, portanto, ao que Assmann denomina memória geracional. A Exposição do Mundo Português de 1940 ajuda a configurar a personalidade do arrivista Delfim Velleno, desolado porque seu papel na organização do evento não recebera o devido reconhecimento político e, portanto, nenhum benefício lhe trouxera. A sombra de Salazar e da repressão do Estado Novo projetam-se sobre toda a mocidade de Camila, em quem traição e tortura geram desencanto e frieza emocional; por outro lado, a posição branda de Portugal com respeito aos judeus, perseguidos pelo Nazismo, associa-se à história da judia Danielle, mãe de Camila, acolhida em Portugal. Os exemplos multiplicam-se ao longo do livro, estendendo-se até à guerra colonial pela manutenção da posse das províncias ultramarinas, em especial Moçambique, fatos que são associados à geração de Natália, cujo pai é guerrilheiro da FRELIMO, e a sua busca pela reconstrução da imagem paterna. 
Uma vez que tenha entrado no círculo individual e nacional de preocupações, interesses e paixões, a história vivida passa a fazer parte da memória histórica (no dizer de Halbwachs) ou social (na tipologia de Assmann). Por outro lado, um fato exterior à vida do indivíduo deixa sua impressão em um dado dia e hora, e a vista dessa impressão o fará recordar a hora ou o dia. Esse é o caso, no romance, por exemplo, do 25 de abril, dia que se associa, na memória de Camila, aos festejos populares e, sobretudo, à memória da pequena Natália, que junto com ela engrossa a multidão que celebra o fim do Estado Novo.

Expus, até agora, os conceitos básicos sobre memória que justificam a presente análise; a seguir, passo a analisar a construção memorial de cada personagem a partir do suporte material em que se desenvolve.

\section{PAIXÃO DA PACIÊNCIA, ALMA DE AZULEJO: O DIÁRIO DE JENNY}

A verdade é que Portugal resistiu, em casulos sucessivos, a todas as decadências, pela paixão da paciência, que sabe sempre rir-se das paixões maiores. [...] o português inventou uma alma de azulejo, pintada e lascada. (PEDROSA, 2011, p. 72)

Em seu O pacto autobiográfico (2008), Philippe Lejeune chama a atenção para o fato de que a identidade individual, na escrita como na vida, passa pela narrativa: colocar algo por escrito corresponde a prolongar o trabalho de criação da identidade narrativa de que consiste qualquer vida. Assim, passar a limpo os "rascunhos de [uma dada] identidade" (preservo a expressão usada por Lejeune) é atitude que se origina da tentativa de um indivíduo de se ver melhor, implicando um movimento de revisão vital que vai estilizar ou simplificar os fatos da vida, e que equivale a uma recriação, na qual a memória necessariamente assumirá papel preponderante. Assim acontece, também, nos diários de Jennifer, em que a protagonista do romance de Inês Pedrosa, já idosa, rememora sua vida.

$\mathrm{Na}$ verdade, o primeiro contato do leitor com a história vital de Jennifer, Camila e Natália se dá através do diário de Jenny, um diário peculiar, uma vez que o reconhecimento do texto como pertencente ao gênero de escrita memorialista somente é possível a partir de elemento paratextual, através do qual se firma o pacto de leitura entre leitor e autor, que denomina a primeira parte do romance de "O diário de Jenny".

Lejeune descreve o diário como forma de memorialística discreta, feito de uma série de vestígios datados, cuja intenção é balizar o tempo através de sequência de referencias: "A base do diário é a data. [...] O diário é um vestígio com suporte próprio [...] O diário é uma série de vestígios." (LEJEUNE, 2008, p. 260, grifos do autor). O diário de Jenny, contudo, carece do registro de datas. Escrito três anos depois da doença e morte de António, o diário, a um tempo rememoração valorativa do passado e registro de vestígios, embora primariamente dirigido a Camila, a fim de desvendar- 
-lhe o segredo de sua verdadeira filiação, é, também, vital na avaliação de Jennifer de sua relação com o marido.

É a este último que se dirige já nas linhas iniciais, quando rememora o primeiro encontro: "A tua cabeça rodou na direção de meu rosto, os teus olhos fecharam-se e a tua boca avançou para a minha, através uma lenta rota de luz, risos e lágrimas." (PEDROSA, 2011, p. 12). Note-se a ênfase, na frase inicial, nos elementos descritivos de relacionamento, o jogo entre tu e eu, teu e meu, associados a uma jornada vital que resume, retrospectivamente, como rota de "luz, risos e lágrimas", antecipando tanto o brilho que a presença e o riso de António trazem a sua vida, como a negação do sonho de tê-lo como esposo-amante, já que jamais pôde chamá-lo de inteiramente seu.

Ao invés de ser escrito em "tempo real", o diário de Jenny é, pois, redigido em retrospecto: não escreve para que deixe rastro de si, através do qual reencontre os elementos do seu passado. Se, nesse sentido, a protagonista difere dos típicos praticantes de um diário, e embora, também diferentemente deles, escreva para um leitor futuro, cujo nascimento já ocorreu - Camila -, preserva uma característica fundamental: em primeiro lugar, e acima de tudo, escreve para si própria. Como o pensador francês discorre, as quatro funções primordiais do diário são: 1) exprimir-se, o que envolve o desabafar e o comunicar; 2) refletir, que abrange tanto analisar, atividade associada às funções de expressão e memória, como deliberar; 3) fixar a vida, conjurando o esquecimento; 4) sentir o prazer de escrever, criando um objeto no qual nos reconhecemos.

Embora as três primeiras funções sejam mais evidentes no diário da protagonista, é inegável que há um prazer, também, no escrever. Ela sabe que, pela palavra, reconstrói e reinventa sua vida, e a de seus queridos. Na segunda entrada do diário, ao explicar a necessidade de contar sua história, registra que esta é a "possível verdade destes setenta e cinco anos que já vivi” (PEDROSA, 2011, p. 19). Sabe, também, que cria um António que não existe: "inventei um homem para sonhar até ao dia branco de nossa eternidade" (PEDROSA, 2011, p. 11); para Camila, confessa: "Os factos, minha querida Camila, não existem, são peças de loto que inventamos e encadeamos para nos sentirmos vitoriosos ou, pelo menos, seguros" (PEDROSA, 2011, p. 18). Analisando a situação do pós-guerra, medita:

A utilidade fez-se valor dominante, os filósofos estudaram ciências naturais, estenderam as inquietações sociais em mesas, como dantes só se fazia à massa dos bolos, aos animais vivos ou aos cadáveres humanos, $\mathrm{e}$ montaram consultórios para resolver as pessoas. E o amor, que não tem resolução, desapareceu.

O tempo tomou-lhe o lugar, mas o tempo gira ao contrário da luz, do branco para o negro por isso é preciso que gire a uma velocidade cada vez maior, para que a vida passe sem darmos por ela. O amor, Camila, é o único travão da morte. (Pedrosa, 2011, p.18). 
Ante o utilitarismo dominante, que acelera o tempo, na ânsia do mais ter, Jennifer opta pelo ser, e elege como essência e garantia de vida o amor, ainda que feito de delícia e dor, como no seu caso. Havendo descoberto, na noite de núpcias, a real natureza da relação entre António e Pedro, sente-se incapaz de enfrentar risos zombadores, e o desolado desprezo da mãe, e opta por permanecer sua namorada, em firme cumplicidade de faz de conta. Ama devotadamente, e com uma paciência submissa de quem aprendeu que "tudo o que há para saber do amor é deslumbrada aceitação" (PEDROSA, 2011, p. 20). Tal como Portugal, em cuja raiz identitária seu amigo Manuel Almada discerne a "paixão da paciência, que sabe rir das paixões maiores", revestindo o que é frágil e quebradiço com insuspeita beleza, Jennifer aprende a cultivar tal alma de azulejo, e a paixão da paciência.

Esse era um tempo em que as mudanças eram lentas e o sentimento de pertencimento ao grupo e a memória de seus membros, intensos; uma época em que a vida, e principalmente a das mulheres, feita de rotinas, exercitava peculiarmente tanto a memória procedural, como a semântica e a episódica, na quotidianidade das vivências individuais e sociais:

Na minha juventude, as mudanças eram lentas e parcelares. Em cada morto crescia um enxame de abelhas (?)para embeber as saudades dos seus próximos. Tudo nos era próximo: opulência, miséria, paixão, desespero, infâmia, hombridade, desfilavam num cortejo vagaroso e circular diante de nós, e demorávamo-nos a dissecar cada uma de suas manifestações. [...]

Éramos mansos porque tínhamos memória [....] Viver era lembrar continuamente, até à náusea, devolver visitas, celebrar nascidos e finados, escrever dezenas de postais num único fim de semana de passeio, amassar sonhos de Natal, pintar ovos de Páscoa, comemorar feridos, estropiados e todos os restantes herdeiros da demência humana. Com a aproximação do novo século, a vertigem de esquecer mascara-se de vertigem de lembrar (PEDROSA, 2011, p. 66).

Assombra a Jenny a aceleração do tempo nos últimos anos do século XX. Lamenta que Natália viva em um mundo veloz, onde as pessoas acasalam como quem une capitais, para lucrar mais. Ante o que percebe como a mercantilização e reificação do amor, Jennifer opõe sua filosofia nascida da prática da "paixão da paciência". Define: "Amor não tem portas que possamos abrir e fechar [...] Habituamo-nos a tratar os amores como eletrodomésticos: quando se escangalham, vamos ao supermercado comprar um novo, igualzinho [...] Substituímos a eternidade pela repetição" (PEDROSA, 2011, p. 70).

Uma vez que o presente é o tempo organizador da experiência humana, a reordenação do passado como base nas concepções e emoções do presente acontece tanto a nível individual como coletivo. Ao pensar a dimensão coletiva em seus cruzamentos com a memória individual, Mau- 
rice Halbwachs enfatiza que a anamnese do indivíduo depende dos que lhe são contemporâneos, já que é a partir da percepção que entretém, em um dado momento, enquanto membro de um grupo, que recuperará fatos de suas vivências. É enquanto matriarca, e, portanto, mulher que pertence à outra geração, que Jennifer avalia a experiência da neta. Curiosamente, também esta concorda com o efeito da banalização gerada pelo "ritmo alucinante de convívio e informação": a Rui interessam igualmente tanto o último disco da Madonna, como a fertilização in vitro ou controvérsias em torno de Heidegger. Natália pensa que a vida perde o sentido: como avalia, tudo se faz com praticidade e rapidez, inclusive matar. Nesse ritmo de pura velocidade, não há tempo nem mesmo para seu arranjo sentimental: casada há dois anos, ainda tem coisas empilhadas pela casa, já que ela e o marido nunca têm tempo para isso.

Halbwachs registra que o lembrar ou o esquecer têm, como um de seus suportes, o espaço compartilhado, já que o ambiente material traz a marca tanto de um indivíduo como do grupo com o qual tal espaço é partilhado. "Nossa casa, nossos móveis e a maneira como são arrumados, todo o arranjo das peças em que vivemos, nos lembram nossa família e os amigos que vemos com frequência nesse contexto", ensina o estudioso francês. (HALBWACHS, 2006, p. 157).

Em contraste com o que acontece com Natália, que, na ausência tanto da vivência da casa em sua materialidade, como de momentos significativos ligados a ela, evita o espaço que deveria chamar de lar, a Jennifer cada recanto da Casa Xadrez lembra momentos compartilhados com a família e seu círculo de amizades. Poucos anos antes de sua morte, registra em seu diário: "As pessoas que morrem entranham-se nas paredes da casa e nas copas das árvores do jardim" (PEDROSA, 2011, p. 61). Relembra os almoços no alpendre, no verão; a sala, que transformara em bar para afastar António dos cassinos e da penúria econômica, os jantares com os amigos, as reclamações de António à mesa, o prazer da refeição estampado em Pedro. Desses pormenores tem saudade, já que avalia que é neles "que a memória se concentra, projetando uma luz tão intensa sobre esses dias mortos que às vezes tem[e] que já não sejam lembranças, mas criações puras da [...] solidão" (PEDROSA, 2011, p. 62).

É justamente porque reconhece um forte elo entre o ambiente material e a preservação da memória de seus queridos que Jennifer mantém a casa exatamente como era quando vivenciada por António e Pedro. É esse também o motivo pelo qual Natália abarrica-se na casa, impede a mãe de vendê-la após a morte da avó, e arrepende-se da intenção inicial de remodelá-la pois que, fazendo assim, iria afastar a avó da Casa Xadrez - a ela, ao avô Pedro, ao António, e ao Manuel Almada, velho amigo de todas as horas.

Jennifer encerra seu diário com um desesperado protesto contra a ameaça de ser interna em um lar, longe de todos os que lhe alimentaram a alma, e ainda nutrem-lhe a memória. Quanto mais esta se esboroa, mais necessário se torna a ela reter aquilo que dá sentido a seu viver: "Quase não te oiço, António; oiço estilhaços de frases, estranhos que ameaçam fechar- 
-me na cave de um lar [...] Não me lembro da tua cara, meu amor [...] mas desejo-te cada vez com mais violência" (PEDROSA, 2011, p. 86).

O diário se inicia e termina com a memória de António, mais especificamente da sensação com o contato físico de seu corpo: ao início, as primeiras carícias, e o primeiro beijo; a intimidade de suas mãos, ao final. A história pessoal, sobretudo a vivida sensualmente, fortemente alimenta a memória de Jennifer. A relação entre memória e suportes sensórios é descrita por Paul Connerton (2012, p. 72), em seus estudos sobre a forma pela qual a memória é sedimentada, como uma prática corporificada ("incorporating practice"): refere-se a atos tais como sorrisos, apertos de mãos ou trocas de palavras, i. e., mensagens emitidas por meio de atividade corporal, cuja transmissão ocorre durante o tempo em que os corpos do emissor e do receptor estão presentes, servindo de suporte para aquela atividade específica.

$\mathrm{Na}$ impossibilidade do contato íntimo pleno, Jennifer pinta os azulejos de sua memória com contatos físicos significativos com os quais possa construir o edifício de sua memória pessoal. Já que outros são os fatos que marcam a vida de sua filha e neta, outros são os suportes e as preocupações que cada uma delas registra em suas memórias: como Jennifer observa, cada uma delas busca uma âncora, fixando-se na nostalgia dos seus trabalhos - Camila, na fotografia; Natália, em casas: coisas que ficam.

\section{FUNDAMENTO DE DESESPERO, BUSCA DA FELICIDADE: 0 ÁLBUM DE CAMILA}

On ne bâtit un bonheur que sur un fondement de désespoir. Jê crois que jê vais pouvoir me mettre a construir. $^{2}$

Marguerite Yourcenar

Replico, como mote para as reflexões em torno da construção da memória de Camila e do suporte material escolhido por ela, a citação escolhida por Inês Pedrosa como epígrafe para introduzir a segunda parte de seu romance, a qual é extremamente pertinente para descrever a vida e o trabalho de memória de Camila.

Das três mulheres fortes cujas histórias se entrecruzam no romance, nenhuma tem a vida tão fortemente marcada pela tragédia quanto Camila. Pouco convive com a mãe biológica, Danielle, judia francesa escapada ao nazismo, militante ativa da Resistência, que, ao intensificar seus trabalhos em prol de seus compatriotas, já não pode conservar junto a si seu bebê. Conquanto Jennifer conte-lhe a história da mãe, cresce ignorando sua paternidade. $\mathrm{Na}$ adolescência, torna-se ativista política, e aos dezoito anos é presa por protestar contra o regime salazarista. É submetida a torturas, entre risos e ameaças, por Carlos Bonito, que, seis anos antes, quando ainda conhecido como Carlinhos Souza, carregara, junto com ela, 
as alianças no segundo casamento de Josefa Nascimento, amiga de Jennifer. É traída, também, por Glória Veleno, a quem julgava amiga, mas que se exime de auxiliá-la, temendo a perda de favores políticos. Resulta disso o ceticismo e a descrença nos afetos humanos, a que se dá trégua durante breve paixão, interrompida bruscamente após um ano, quando Eduardo morre fulminado por um raio. Abandonando o lugar onde pensara poder construir a felicidade, vai a Moçambique como repórter de guerra; lá encontra Xavier Sandramo, guerrilheiro da FRELIMO, de quem fica grávida de Natália. Ambos não têm tempo de construir vida a dois: pouco depois da relação com Natália, Xavier é assassinado. Frente aos repetidos golpes, Camila fecha-se em si mesma, desesperançada: tem dificuldade de abrir-se ao outro, e expressar seus sentimentos. Na avaliação de Jennifer, a filha põe nas fotografias o rigor que não encontra na vida, e, sempre que as pessoas a magoam, fecha-se na câmara escura.

Em meio a repetidas traições, Camila busca inicialmente, nas fotos, a função testemunhal: pensa, então, que estas podiam fixar a verdade para sempre. Barthes atribui o papel autenticador da foto à confusão entre dois conceitos: o real e o vivo. Ao atestar que um objeto foi real, a foto leva a acreditar que está vivo. Contudo, esse real é deportado para o passado ("isso foi"); a função da fotografia não é atestar o que foi extinto, mas de testemunhar que algo ou alguém realmente existiu. Tocando-nos "como os raios retardados de uma estrela", a foto é uma emanação do referente: de um corpo que existe (ou existiu), partiram radiações que nos atingem. (BARTHES, 1984, p. 122- 125). Na nomenclatura de Barthes, o fotografado, ou referente, é o alvo, o spectrum da fotografia, palavra que evoca tanto a relação com o espetáculo, quanto o "retorno do morto", o instante fugidio capturado pela foto.

Tal retorno é particularmente importante para Camila, que precisa apaziguar-se com os seus mortos: com a mãe e Eduardo, afetos que lhe foram roubados; com Xavier (menos como homem, mas como símbolo da África e do desejo de liberdade), com Lisboa, que percebe como cidade enevoada, símbolo do Portugal de seus anos formativos, e que remete, também, a seu passado de guerrilheira e da experiência de ter sido traída e torturada. Por esse motivo, organiza um álbum para si. Nisso difere do pai de família descrito por Bourdieu, que ao organizar o álbum de família pensava, sobretudo, prover a seus filhos, como legado, a imagem dos que se foram. Nessas imagens do passado, dispostas em ordem cronológica, o grupo vê os acontecimentos que merecem ser conservados porque retêm, do seu passado, a confirmação de sua unidade presente: o álbum, Bourdieu compara, tem o brilho quase presunçoso de monumento do passado frequentado assiduamente (BOURDIEU, 1965, p. 53-54).

Se tem a si, antes que aos outros, como objetivo maior da composição do álbum, Camila necessita da função memorial da foto - memória entendida como construção rememorativa e criativa. Como qualquer texto, também as fotos necessitam ser interpretadas. Sua realidade própria não 
corresponde necessariamente à realidade do assunto fotografado; o realismo fotográfico se refere, antes, à realidade do documento fotográfico, que é já uma segunda realidade, como comenta Kossoy (1993). Disso decorre que a interpretação das imagens variará não somente de leitor para leitor (o spectator, de Barthes), mas também de acordo com as coordenadas de situação de cada um, i. e., seu espaço e tempo distintivos.

É, pois, a partir de sua história de vida, e sob a ótica retrospectiva de seu momento presente, que Camila analisa as fotos e reconstrói sua vida. Dispostas em ordem cronológica, de 1941 a 1994, data de seu autorretrato, as fotos atestam preocupações centrais para a personagem: precisa reconstruir a imagem da mãe (primeira foto, a única não criada por ela própria), entender os homens de sua vida (fotos de Eduardo, Xavier), confirmar a validade de suas posições éticas enquanto fotógrafa (fotos de Salazar em lágrimas, que se recusa a publicar, e de Maurice Béjart, incitando à luta contra o fascismo, que é recusada pelo editor), repensar traições (fotos de Glória Velena e de Armanda), avaliar a relação da mãe com Pedro e António (foto do trio no jardim da Casa Xadrez), pensar a filha e a si mesma (fotos de Natália e autorretrato).

Fotógrafa que é, Camila bem sabe as peculiaridades estéticas de seu meio de expressão, e os fundamentos que regem a expressão fotográfica. Para além do plano iconográfico, percebe a complexidade das informações contidas nas representações fotográficas, que, como Kossoy (1993) comenta, são portadoras de significados não explícitos e de omissões calculadas. No dizer do teórico, as imagens fotográficas

não se esgotam em si mesmas, pelo contrário, elas são apenas o ponto de partida, a pista para tentarmos desvendar o passado. Elas nos mostram um fragmento selecionado da aparência das coisas, das pessoas, dos fatos, tal como foram esteticamente congelados num dado momento de sua existência/ocorrência. Seu potencial informativo poderá ser alcançado na medida em que esses fragmentos forem contextualizados na trama histórica em seus múltiplos desdobramentos [...]. Caso contrário essas imagens permanecerão estagnadas em seu silêncio: fragmentos desconectados da memória (KOSSOY, 1993, p. 14, grifo do autor).

Tomando cada uma das fotos como ponto de partida, Camila reavalia sua vida, da gravidez de sua mãe à idade adulta. No comentário que se segue a cada foto, não se atém ao instante capturado, mas o explora através de complexas redes de associações. Assim, por exemplo, ante a foto de Eduardo, datada de 1962, rememora sucessivamente sua morte, o dia em que a foto foi tirada, e seus planos artísticos e políticos de então; contrasta a mentalidade da mãe de Eduardo e a de Jennifer com respeito ao relacionamento pré-matrimonial; retrocede à prisão e à tortura, e ao esvaziamento afetivo que estas lhe causam. Relembra, depois, o poder restaurador da paixão por Eduardo e a saudade de sua presença, e culmina as recordações 
com a avaliação de sua ida à África como uma tentativa de enterrar a dor da morte do amado.

Como ponto de partida de sua rememoração, Camila busca nas fotos aquilo que Barthes denominou de punctum, em oposição a studium. Enquanto este último designa um tema e seus signos correspondentes, punctum aponta aquilo que, numa foto, punge, mortifica, fere. Na foto da mãe impressiona-a seu sorriso, e os olhos que sobressaem como dois riscos de luz. Gosta de pensar que é ela que a faz sorrir; não lembra a voz da mãe, e tudo o que pensa dela ter ouvido está nesse retângulo de luz, no riso que a guiou na alucinação dos dias de tortura.

Camila pensara que as imagens poderiam prover-lhe cura à alma, que poderia "colar os instantâneos do mundo sobre o sangue do [seu] coração e fazê-lo parar. [...] Pensei de mais". (PEDROSA, 2011, p. 129). São precisos trinta anos para que encare com serenidade a experiência africana e os fatos que a precederam, e exponha as fotos feitas em Moçambique. Aos cinquenta e dois anos, finalmente começa a gostar de si; dá-se conta de que tem "uma história com o seu jubiloso manto de mortos". Nesse momento, faz seu único autorretrato: uma mulher com o olhar sereno, com uma câmara fotográfica na mão. Já agora pode construir a felicidade sobre um fundamento de desespero.

\section{CANIBALISMO EMPERRADO DA MEMÓRIA: AS CARTAS DE NATÁLIA}

[...] tropeço ainda demasiado no canibalismo emperrado da memória: vivo do sabor adocicado que os mortos deixam no meu corpo. Um sabor grande, Como Moçambique. (PEDROSA, 2011, p. 198)

A epígrafe aparece, no contexto do romance, na nona e penúltima carta de Natália à avó, a primeira que dedica a ela depois de sua morte. Esse é um momento em que a saudade e a memória de Jennifer se faz mais intensa, e se confunde com a de outros amigos já falecidos, como Helena e Manuel Almada. Natália raciocina que estes já se encontram em um plano infinito, onde a saudade e o culto das ruínas traduzem um saber maior, uma aprendizagem de bem viver gerada a partir da dor. Registra seu desejo de passar a esse plano, no que é impedida pelo "canibalismo emperrado da memória".

Talvez nada pudesse sugerir melhor a comunhão com os outros e o desejo de absorção de suas lições de vida do que o canibalismo, prática que, como se sabe, repousa sobre a reverência ao morto, cujas qualidades o canibal aspira passar a adquirir. No entanto, o canibalismo de Natália é emperrado, insaciado e, no momento, insaciável, dependente da memória dos que se foram, uma memória que se confunde com a busca de raízes pessoais e, também, com sua memória geracional, a história vivida que alimenta sua formação identitária. 
Nesse contexto, em que a partilha memorial é imperativa, cartas, que por definição devem ser compartilhadas, são particularmente adequadas como suporte de memória. Como Lejeune assinala, há sempre mais de uma pessoa envolvida na escrita de cartas, que são, a um tempo, objetos que se trocam e atos que podem ser publicados. (LEJEUNE, 2011, p. 252).

Comentando o emprego de cartas enquanto recurso de memória, Halbwachs descreve-as como um dos meios usados quando, por força da distância, membros de um grupo necessitam dar a conhecer uns aos outros detalhes que lhes escapariam pela falta de contato, de forma que o que de suas experiências fosse estranho ao outro é assimilado em seu pensamento comum (HALBWACHS, 2006, p. 51). Embora as cartas de Natalia sejam, obviamente, uma forma de contato com a avó, a "querida Jenny" a quem se dirige ao início de cada missiva, é evidente que a distância não é o motivo fundamental para a escrita, já que, com exceção de duas, todas as cartas são redigidas em Lisboa, cidade em que avó e neta moram.

Datadas e cronologicamente ordenadas, de maio de 1984 a outubro de 1994, quando já a avó estava morta, as cartas parecem cumprir, para Natália, as mesmas finalidades que o diário cumpre para a sua avó. Nelas percebe-se a necessidade de desabafar, comunicar e registrar fatos como forma de exorcizar o esquecimento, e de reconstruir momentos relevantes que a ligam ao círculo familiar e de amizades. As cartas têm, ainda, a função de, retrospectivamente, analisar a vida, o que as torna tão verdadeiramente objeto de autoconhecimento como as fotos o são para Camila. Natália mesma reconhece que, apesar da diferença de suporte, tanto a mãe, com seu trabalho nas "máquinas de fugir à vida", quanto ela, em suas edificações, tornam-se "caçadoras da luz", em trabalho incessante de recordação. Afinal, como descreve, tal qual sua mãe, traz também no sangue a "calada paixão pelos amores mortos, esta determinação de só depois entender o essencial, de amar as distâncias como única proximidade do céu." (PEDROSA, 2011, p. 137).

Como Camila, que faz das fotos o meio e metáfora para analisar a vida, Natália busca em sua profissão de arquiteta a compreensão e expressão dos fatos que a atingem, ferem e incitam à ação. Retrocedendo a sua infância, localiza o gosto pelas formas em uma educação para a alegria, possivelmente herdada do pai e da mãe, mas também do exemplo de Jenny e Rosário, que lhe ensinam a ver o mundo como um lugar transformável, cheio de possibilidades. A arquitetura parecera-lhe "o único modelo de arte onde a ideia de responsabilidade social podia ainda sobreviver sem troça. Uma arte onde o grande imperativo da liberdade se podia ainda exercer com um propósito altruísta, escapando à frívola fantasia combinatória destes anos de contínua reinvenção individual." (PEDROSA, 2011, p. 143-144).

No entanto, percebe que os tempos mudam, e que esse modelo idealista de arquitetura desaparece ante o deus da ostentação. O dinheiro a tudo domina; foi-se a generosidade que, no tempo da avó, ampliava as ca- 
sas e transformava o pouco em banquete. Ao contrário, a ânsia de ter descamba em extravagantes construções, que a estiolam, como a remodelação de interiores, em que tem de transformar uma capela em um bar-discoteca, decorado com luzes e toda a família Disney, ou as colunas gregas "iguais às da Acrópole" espalhadas em uma sala de jantar, a pedido dos donos.

Natália pensa a relação com Rui como uma construção. Quando a morte da avó a leva a pensar sua própria história de vida, decide acabar o casamento com Rui, justificando: "Eu e o Rui caímos no mais comum dos erros românticos, que é o de tratar as afeições como projetos de arquitetura" (PEDROSA, 2011, p. 181).

Durante o divórcio, quando Rui e ela se olham como antigos amantes, avaliam a experiência passada através de doloroso processo que se move entre o lembrar e o esquecer. Consideram: "o que no próprio corpo esquecemos, aprendemos, aprendemos a esquecer, esquecemos de aprender." Parece A Natália que tudo lhe anoitece na memória, e lembrar torna-se, para ela, “a declinação vertiginosa do esquecer." (PEDROSA, 2011, p. 185-86).

Horroriza a Natália a perspectiva de, uma vez chegada ao fim da vida, perceber-se como uma daquelas mulheres cujas vidas jamais ousaram desenrolarem-se, vítimas daquilo que define como a súmula de todos os erros da terra: a evitação de vida. Embora, retrospectivamente, perceba que teve medo da paixão, desistindo de Álvaro, sente depois que proceder assim seria insultar a "memória do [seu] sangue", feito da mesma massa que o de Jenny.

Já a avó percebera a semelhança da neta para consigo: como ela, Natália receia a intimidade; não tem tempo para o amor. Deposita a fé e a paixão nas casas que constrói, mas Jennifer a adverte: também estas não têm tempo, são transitórias. Construídas de vidro e alumínio, as casas que planeja logo estarão enferrujadas, e darão lugar a outros prédios, mais modernos e baratos.

Recordando a amizade com Leonor, Natália afirma que os amigos são a única hipótese durável de sobrevivência da infância. Nisso parece estar a ecoar a concepção de Halbwachs acerca do fortalecimento da memória a partir da manutenção de laços afetivos com membros de um dado grupo social. Assim também se explicam as alternativas de aprender a esquecer no momento em que tais laços se desfazem; mais: é justamente face ao "esquecimento" de aprender, face à falha em cultivar elos duráveis, que o esquecimento se impõe.

Natália confessa a sua amiga Leonor que o objetivo de sua vida é construir edifícios, e, se possível, "compensar a ausência de um alicerce fundamental." (PEDROSA, 2011, p. 155). Se é a separação da mãe que primeiro ocupa a atenção de Camila em seu álbum de fotos, a Natália o problema fundamental é ir à busca da memória do pai, em Moçambique, a fim de desvendar a história daquele de quem foi gerada. Esse é um desejo adiado até 1994, quando, seis meses depois da morte de Jenny, Natália se desloca para 
Moçambique, então ás vésperas da primeira eleição livre, mas claramente ainda devastado pelos efeitos da guerra. Identifica-se com os moçambicanos, "herdeiros de ruínas"; desloca-se para Xai-Xai à procura da história de Xavier Sandramo. É bem sucedida, já que encontra um velho sobrevivente que conheceu a seu pai, e que lhe garante que este morreu grande, como Moçambique, ideia que ela repete, com variantes, ao falar do sabor adocicado do seu antropofagismo memorial, grande como Moçambique.

Cabe a Natália pensar a reconstrução de sua própria vida, tarefa para a qual sente-se desafiada e pronta após decidir cessar com atos de ocultação de vida: termina o casamento com Rui, vai à Moçambique em busca de suas raízes e, ao descobrir a persistência da paixão por Álvaro, busca-o, atraindo-o com a mesma frase com a qual, anos antes, Jennifer tentara, em vão, seduzir a António. Em contraste com a avó, Natália é bem sucedida, rompendo a série de relacionamentos não correspondidos ou interrompidos que caracterizaram a vida dessas três mulheres.

\section{CONCLUSÃO}

Três mulheres, três gerações, uma pátria: eis os elementos que, escolhidos por Inês Pedrosa para tecer a trama do romance, singularmente se prestam ao estudo do trabalho de memória. A opção por mulheres da mesma família, de sucessivas gerações, e, portanto, com diferentes visões de mundo, põe em evidência não somente as diferenças individuais e geracionais como fornece contexto extremamente pertinente para o cruzamento da memória pessoal e social. Se a proximidade do grupo familiar facilita o desenvolvimento do senso de pertença, também revela com mais clareza diferenças pessoais e conceituais; por outro lado, como o período formativo de cada geração se dá em época distinta, o contexto intergeracional propicia revisão de amplo e significativo período da história de Portugal, percebido, a partir de diferentes ângulos, por essas mulheres.

Nesse processo, avultam em importância os suportes analíticos escolhidos, todos eles ligados a escritas ou visões do eu. Permitem, portanto, uma releitura do mundo que, embora baseada na vivência dos círculos familiar, de amizade, ou de trabalho, revela a mundivisão individual. Por fim, uma palavra sobre o construir, metáfora que subjaz à experiência memorativa e vital dessas mulheres: esta é uma figura especialmente adequada não só para descrever seu trabalho da memória, como para apontar para sua experiência, já que seus mundos, de diferentes maneiras e por motivos diversos, estão em ruínas. Daí a urgência em construir, possibilitar experiências vitais viávies, para si e seu país, que lhes permitam, mais que sobreviver, abandonar toda a ocultação de vida, toda a superfície disfarçada por sob azulejos pintados, toda memória que permanece emperrada, e (re)construir a vida, ainda que a partir do desespero. 


\section{REFERENCIAS BIBLIOGRÁFICAS}

ASSMANN, Aleida. Memory, individual and collective. In: GOODING, Robert; Tilly, Charles. The Oxford handbook of contextual political analysis. New York: Oxford, 2011, p. 210-224.

BARTHES Roland. A câmara clara. Rio de Janeiro: Nova Fronteira, 2008.

BOURDIEU, Pierre. Un art moyen: essai sur les usages sociaux de la photographie. Paris: Minuit, 1965.

CONNERTON, Paul. How societies remember. 20th ed. New York; Cambridge, 2012.

HALBWACHS Maurice. A memória coletiva. São Paulo: Centauro, 2006.

KOSSOY, Boris. Estética, memória e ideologia fotográficas: decifrando a realidade interior das imagens do passado. Acervo: Revista do Arquivo Nacional. Rio de Janeiro, v. 6, n. 1-2, p. 13-24, jan 1993.

LEJEUNE, Philippe. O pacto autobiográfico: de Rousseau à Internet. Belo Horizonte: Editora UFMG, 2008.

PEDROSA, Inês. Nas tuas mãos. Rio de Janeiro: Objetiva, 2011.

Recebido para publicação em 15/05/2013

Aprovado em 30/08/2013

\section{NOTAS}

1 Reproduzo, aqui, a datação da morte de Sidónio Lopes apresentada no romance. Na verdade, esse fato histórico não aconteceu em 1914, mas a 14 de dezembro de 1918.

2 Não se constrói a felicidade a não ser sobre um fundamento de desespero. Creio que poderei iniciar a construção. (Tradução da autora) 